Note: This is a pre-copy-editing, author-produced PDF of an article accepted for publication in Addiction following peer review. The definitive publisher-authenticated version [Alcoholics Anonymous in Ireland: AA's first European experience, Addiction, 102(6), 879 - 886] is available online at http://www3.interscience.wiley.com/journal/117967974/abstract

\title{
ADDICTION HISTORY
}

\section{Alcoholics Anonymous in Ireland: AA's first European experience}

\section{Shane Butler \& Tony Jordan}

Addiction Research Centre, School of Social Work \& Social Policy, Trinity College Dublin

Correspondence to:

Shane Butler

School of Social Work \& Social Policy

Trinity College

Dublin 2

Ireland

E-mail: sbutler@tcd.ie 


\title{
Alcoholics Anonymous in Ireland: AA's first European experience
}

\author{
Shane Butler \& Tony Jordan
}

\begin{abstract}
Aims To trace the evolution of Alcoholics Anonymous in Ireland from its establishment there in 1946, focusing on the efforts of early members to publicise the fellowship and negotiate a role for themselves in relation to existing religious and healthcare institutions. Methods Archival research, mainly drawing on primary sources in AA archives in New York and Dublin. Results Anticipated tensions between this fellowship, which had its roots in Evangelical Protestantism, and the politically powerful Roman Catholic Church in Ireland were skilfully avoided; initial hostility from the medical profession quickly dissipated; and AA distanced itself from policy debate on the wider topic of alcoholism as disease. Conclusions The relatively smooth introduction of AA to Ireland, the first European country in which it was established, may be attributed to the essentially pragmatic nature of the fellowship and the strategic abilities of its early members.
\end{abstract}

Keywords Alcoholics Anonymous, Ireland, Roman Catholicism, temperance cultures, disease concept. 


\section{INTRODUCTION}

In his authoritative history of Alcoholics Anonymous (AA) Kurtz [1] noted that 'in a score of ways, Alcoholics Anonymous was at least by association as American as baseball, apple pie and the Fourth of July' (p.164), and in the recent resurgence of AA studies (e.g. Eisenbach-Stangl and Rosenqvist [2]) there has been much interest in understanding how such an obviously American movement was diffused so successfully internationally. The largest such study, the International Collaborative Study of Alcoholics Anonymous (ICSAA), presented detailed accounts of how AA functioned in eight widely differing societies, summarily commenting (Makela, Arminen, Bloomfield et al. [3]) that 'Founded in the United States, and with its headquarters still located there, AA spread first to other English-speaking societies, and to societies that had a strong Protestant-oriented temperance tradition' (p.239). This comment is broadly reflective of Levine's [4] argument that AA was most readily intelligible and acceptable within Protestant 'temperance cultures'.

However, the first European country to which AA was diffused was Ireland, an English-speaking but predominantly Catholic country. Ireland was not included in the ICSAA and the aim of this paper, which draws primarily on archival material, is to fill this gap by providing an account of the establishment of AA in Ireland in 1946 and of its survival over its first quarter of a century in this country. The starting point for this history is that AA occupies what Valverde and White-Mair [5] describe as a 'hybrid terrain' between the institutions of religion and medicine. In relation to religion, this study will focus specifically on the potential for conflict between AA, which had its roots in the Protestant Evangelical tradition of the United States, and the then politically powerful Roman Catholic Church in Ireland. From a healthcare perspective, the study will consider both early relationships between AA and the medical profession and the wider question of how AA's cultural framing of 'alcoholism' resonated with Irish health policy. On this latter issue, the paper will trace AA's Irish history across three identifiable periods: an early period in which the disease concept of alcoholism gradually gained acceptance within Irish health policy, a middle period during which the disease concept was officially enshrined as an 
integral part of health policy, and a final period which saw the first stirrings of revisionist ideas about the validity and utility of the disease concept.

\section{IRELAND IN THE 1940s: THE HISTORICAL CONTEXT The Influence of the Catholic Church in Independent Ireland}

The Irish Free State, into which AA was introduced in 1946, had a population which was almost 95 per cent Catholic. Inglis [6] describes the Catholic Church in Ireland at this time as enjoying a 'moral monopoly', which he explains using the concept of religious habitus (borrowed from the sociologist Bourdieu): 'By habitus, Bourdieu means a lasting, general and adaptable way of thinking and acting in conformity with a systematic view of the world which, in our case, is that of the Catholic Church' (p.11).

However, even if Church influence on social policy was usually mediated indirectly and through a broad cultural consensus as to the moral rightness of the Catholic viewpoint, the situation in Dublin - where AA established its first Irish group - was significantly different owing to the more interventionist societal role played by the then Catholic Archbishop of Dublin, John Charles McQuaid. Amongst historians (e.g. Cooney [7]; Keogh and McCarthy [8]) there is agreement as to the sharpness of McQuaid's intellect and the sincerity of his commitment to the provision of health, welfare and educational services within his archdiocese, but also as to the narrowness of his doctrinal views, the rigidity of his authoritarian personality and the proprietorial attitude he had towards the city of Dublin. McQuaid was intolerant of Protestantism and generally antagonistic towards interdenominational health, welfare and educational initiatives.

From the perspective of the Catholic Church in Ireland during the mid-1940s, there was much about AA to arouse suspicion. The fact that in the United States AA had grown out of the Oxford Group, a non-denominational Christian movement aimed at recreating the spirit of primitive Christianity, would in itself make this organisation suspect; and its Twelve Step programme of recovery - with its talk of a 'Higher Power', 'God as we understood him' and 'moral inventory' - presented itself 
essentially as a non-denominational and lifelong 'spiritual' fellowship which might easily have been seen as a rival to the moral monopoly of the Catholic Church in Ireland. To Irish Catholic bishops, who favoured a centralised teaching authority, the AA approach to governance - based on a cell structure which gave maximum autonomy to individual groups and to 'group conscience'- must have appeared puzzling if not anarchic. Finally, given the deference to which he was accustomed, McQuaid might well have taken umbrage simply because the founders of AA in Dublin had not sought his blessing for this venture.

\section{Public Policy and Temperance Views on the Drink Problem in 1940s Ireland}

As a predominantly Catholic country, Ireland was not a 'temperance culture' as defined by Levine [4] and its best-known Catholic temperance movement, the Father Mathew temperance crusade of the late-1830s (Malcolm [9]), flourished briefly but ultimately failed for two reasons: the lack of organisational skills of its founder, and the reluctance of Catholic bishops to sustain a movement which appeared suspiciously Protestant in its aggressive rejection of alcohol. The mainstream and ideologically moderate Catholic temperance movement in Ireland, the Pioneer Total Abstinence Association, which was established in 1898 and was still hugely popular in the 1940s, viewed alcohol as a Divine gift from which Catholics could voluntarily abstain (Ferriter [10]). Although it is difficult to identify any consistently articulated perspective on alcoholism within the Pioneer movement, the dominant view would appear to have been one which was sceptical about conceptualising alcoholism as a disease and which emphasised the volitional nature of drinking: people drank because they chose to and could, if they so desired, become and remain abstinent particularly by using their Church membership to invoke God's help.

The lunatic asylums had been routinely admitting problem drinkers all through the nineteenth century, and Finnane [11] estimated that by the end of this century asylum administrators were attributing about ten per cent of all admissions to intemperance. Such admissions were handled pragmatically, in the sense that problem drinkers were admitted, allowed to become alcohol free and discharged sooner than other inmates all without the emergence of any coherent vision of alcoholism as a disease. Although the Mental Treatment Act, 1945, made specific provision for the voluntary and compulsory admission to psychiatric hospitals of 'addicts', there is no evidence that 
this provision reflected a well thought out ideological shift towards a disease concept of alcoholism. Butler ([12] pp.22-25) has noted that the addiction provisions in this statute were added belatedly, were not accompanied by any practical proposal to create new treatment arrangements, and were essentially a continuation of the ambiguous approach of the mental health system towards problem drinkers which had existed for the previous century. Significantly, neither the word 'alcoholism' nor any ideas broadly corresponding to what this concept was coming to mean in the United States were enunciated during the brief parliamentary debate on this topic.

\section{AA IN IRELAND: AVOIDING THE CENSURE OF THE CATHOLIC CHURCH}

The bare facts of how AA came to be established in Dublin have been rehearsed in a number of places, notably in the souvenir booklets published by the AA General Service Office on the occasion of the fellowship's fortieth and fiftieth anniversaries in Ireland [13, 14]. Briefly, what happened was that a visiting AA member, Conor F., originally from Ireland but resident in Philadelphia, decided while on holiday in Ireland to start an AA group in Dublin. His early efforts proved futile, and he was apparently told by some priests whose help he sought that there were no alcoholics south of the border and that people wishing to stop drinking need go no further than the Pioneer Total Abstinence Association [13]; his final thought was to contact the city's psychiatric hospitals with a view to meeting patients being detoxified there. Conor first visited Grangegorman, Ireland's oldest and largest public mental institution; here he was received with interest by the Resident Medical Superintendent who borrowed a copy of AA's Big Book and asked Conor to return a week later. On his return visit, however, he was greeted aggressively by this psychiatrist who questioned the authority of a layman to contribute in any way to the care of his patients, ordering Conor to 'take my books and literature and never come back' [15]. The next institution visited by him was St. John of God's Hospital, a private facility run by a Catholic religious order whose Provincial told Conor that AA was of no interest because 'they never did have alcoholics and never would have alcoholics' [15]. 
It was to be third time lucky for Conor because the response of the medical director of St. Patrick's Hospital, Dr. Norman Moore, was one of civility and interest, leading to the holding of, not just Ireland's, but Europe's first AA meeting on November 18, 1946. From the outset, however, Irish members of AA were conscious of the fact that having its origins in St. Patrick's Hospital might not be the most auspicious start for the fellowship in this country. Conor's own words on the subject were: 'And finally, the place that I didn't want to go - possibly it was the last port of call, the last resort - was St. Patrick's Hospital. I knew I came from the other side of the fence when I talked to Dr. Moore' [15]. The fence in question was religious because St. Patrick's, in the parlance of the day, was a 'Protestant hospital', having been founded in 1746 with money bequeathed for this purpose by Jonathan Swift, the political satirist who was also an Anglican clergyman (Malcolm [16]). To further complicate matters, the first resident Irish member of AA - Richard P. who had been a patient in St. Patrick's when Conor visited there - was also Protestant.

In January 1947, Conor returned to the United States leaving Richard to continue the leadership role within Dublin's AA group which he had already assumed. From the outset, Richard established contact with AA headquarters in New York, writing a number of times to advise the New York secretariat of what progress was being made in Dublin and seeking suggestions as to how difficulties might be tackled. The most frequently recurring theme in this correspondence concerns the fear that $\mathrm{AA}$ in Ireland might be perceived as an insidious Protestant plot and, therefore, a suitable subject for attack by the Catholic Church. In his second letter (December 11, 1946) to New York, Richard explained that:

There is, as you probably know, very strong religious feeling in Ireland, and most public halls are connected with some Church or other. Consequently no such rooms or halls are suitable for A.A. meetings. A Catholic member would not wish to go to a Protestant hall or house and 'vice versa'. Personally, although I am a Protestant, and nearly all the other members are Catholics, I do not mind where I go, but many of the others have strong views on the subject [17].

The response from Roberta ('Bobby') Burger at the New York secretariat was nondirective, merely acknowledging that the religious culture of Ireland was as it was and that 'we $[\mathrm{AA}]$ do not intend to, nor could we, change a basic mode of life, but rather 
we fit ourselves into things as we find them' [18]. To illustrate his difficulties, Richard again wrote to Bobby Burger enclosing a copy of a letter he had received from a Dublin journalist whose help he had sought; in part, this letter read as follows:

If any way can be devised by which the queer suspicions about AA which I find exist in many quarters can be dissipated, it will give great impetus to the movement. Because the movement originated in America - "the land of freak religions" - there is a dumb feeling that it resembles in some way the "Moral Rearmament" campaign which has been completely discredited, I think, across the channel as well as in this country.

In view of the strictly non-sectarian nature of the AA movement, it would not be advisable to have ministers of any denomination patronise it in this country, I believe, but it is possible that they have come out openly in its support in the United States. If this has happened, it would be very effective, I think, if some of their utterances were published over here - particularly any words of cheer and encouragement that were spoken by Bishops or priests of the Catholic Church. In the existing situation I am debarred - through no fault of my own - from giving you the Press support that I would like to give, and I am anxious that this barrier should be removed [19].

These comments are interesting not just because they indicate some of the negative views about AA then current, but also in that they reveal a more detailed knowledge of the fellowship's origins than one might expect of its Irish critics. The founders of AA had indeed been influenced by the Oxford Group, which had transmuted in the late-1930s into the 'Moral Re-Armament' movement, but Bill W. (co-founder of AA) had been acutely aware of negative publicity attaching to this movement and had been shrewdly selective about the elements of its philosophy which he adapted for AA (Kurtz [1] pp. 48-51). Again, Bobby Burger's reply was non-directive, merely suggesting that it would be helpful for AA in Ireland to create its own contacts with Catholic priests who might publicly express support for the fellowship [20].

In April 1947, Dublin AA was joined by a new member, Sackville O'C.M., who quickly became Secretary to the group. Because of his chronic alcoholism, Sackville had been given early retirement from the British Army where he had served as an officer during the two World Wars; however, having become sober through AA, he was ideally suited to contribute to its consolidation in Ireland, being well educated, 
having good organisational skills, and - perhaps most importantly - being a devout Catholic. Sackville's analysis of the task facing him was summarised thus:

Two things were evident from the start:

(a) either the Catholic Church in Ireland was made an ally or AA was sunk, and

(b) either AA publicised itself in Dublin or it would perish of dry rot [13].

On the latter point, Sackville proved to be highly skilled in his use of both print and broadcast media, all of which were consistently supportive of AA. It was, however, his attempts to forge alliances with the Catholic Church in Ireland which featured most regularly in his letters to AA headquarters in New York. What emerges from this correspondence is a strategy on the part of Sackville of avoiding conflict with potentially hostile members of the Catholic Hierarchy while simultaneously promoting AA amongst sympathetic church leaders, particularly by forging links with St. Patrick's College Maynooth, Ireland's national seminary. Writing to Bill W. in January 1950, he announced that: 'At present, I am endeavouring to soften the clerical influence, which is a big factor in this country. I have a promise of a short article in the leading priests' paper [The Furrow], produced by Maynooth College, the great Catholic seminary' [21]. He cultivated this relationship with Maynooth and specifically with the editor of the The Furrow, a journal of pastoral theology published by Maynooth. This resulted not only in regular invitations to lecture students for the priesthood in Maynooth and other Catholic seminaries, but also in the publication of no fewer than seven articles - either by AA members or by theologians - in The Furrow between 1952 and 1960. During these years, through a combination of strategic organisational skills and theological sophistication, Sackville succeeded in persuading Church leaders that the AA approach to spirituality was in no way incompatible with conventional Catholic religiosity, thereby saving the fellowship from any direct assault from this quarter.

In October 1960, Sackville was one of three speakers invited to speak about alcoholism at a conference on the theme of 'The Priest and Mental Health', held at St. John of God's Hospital and officially launched by Archbishop McQuaid. A lingering nervousness may be discerned in the presentation by Father Sean O'Riordan [22], a theologian who had written in support of AA throughout the 
previous decade - 'Some priests have been chary about invoking the help of this movement $[\mathrm{AA}]$ because of its undenominational character. Would not a similar movement but on specifically Catholic lines, they ask, be much better suited to our conditions? (p.152).' However, the inclusion of an AA speaker suggested that the fellowship's programme was no longer seen as a challenge to Catholic spirituality. Fellowship meetings had previously been held in Catholic halls in rural areas but, writing to Bill W. in April 1961, Sackville described how a Dublin group which had lost its rooms had now been accommodated in a hall which was owned by the Catholic Archbishop of Dublin: 'This will be a distinct feather in our caps, having him so to speak on the right side of the fence openly for the first time' [23].

With the help of the Apostolic Nuncio to Britain and accompanied by an English Catholic member of AA, Sackville visited the Vatican in January 1972 where he met with a wide range of influential Church figures, culminating in a private audience with Pope Paul VI. He lost no time in publicising this visit to the Vatican, reporting in the March 1972 issue of The Furrow [24] that :

The Pope graciously greeted us not only for our own sakes, but for the work we were engaged on (i.e. Alcoholics Anonymous), which he described as fine work, a real apostolate. He urged us to press on with our work, gave it his blessing and told us that he would keep it and us in his prayers (p.182).

With endorsement like this from the Pope, AA in Ireland no longer had any real fear of being censured by the local Catholic Church.

\section{AA AND THE IRISH HEALTHCARE SYSTEM}

The second element of AA's 'hybrid terrain' is the healthcare system, and the intention here is to explore how the fellowship negotiated its relationships with members of the medical profession in Ireland, and also how it handled the policy implications inherent in the wider proposition that 'alcoholism is a disease'.

Despite the initial rebuffs experienced by Conor F., subsequent dealings with Irish psychiatrists generally proved to be non-contentious. Based on his personal experience of being treated within the psychiatric system, Sackville was sceptical 
about the contribution of those he referred to in an early letter to Bobbie Burger and Charlotte Lappen as 'trick cyclists' [25]; but, suppressing these views, he gradually succeeded in getting consent for fellowship members to visit psychiatric hospitals where they made contact with patients who were being detoxified. Less than six months after his own first meeting, he was writing to Bobbie Burger that 'I think that with any luck we will have managed to put a foot into one of the private homes for alcoholics shortly' [26] and the following year he was telling her that the clinical director of a mental hospital had sought his views on the treatment of alcoholism and had agreed to try out one of Sackville's suggestions - 'I told him that if he wanted me to see any of his alcs (sic) I should prefer to do so whilst they were sick and sorry and not as at present 6 weeks afterwards' [27]. The archives contain no reference to disagreements between $\mathrm{AA}$ and the mental health system and, even if Irish psychiatrists of this period were privately as sceptical about AA as Sackville was about psychiatry, surface relationships between the two parties proceeded smoothly. The most obvious explanation for this is that Sackville and his fellow-members adhered scrupulously to the Twelve Traditions (the fellowship's administrative code), which make it clear that AA is a non-professional fellowship and, as such, challenges neither the sapiential authority nor the financial status of psychiatry. That a psychiatrist should seek advice on alcoholism treatment from an AA source, less than two years after the fellowship had been established in Ireland may be viewed as indicative of two key facts: one is the previously alluded to therapeutic ambiguity surrounding alcoholism treatment in Ireland at this time, and the second is the skill displayed by early members in convincing psychiatrists that AA had an approach to treatment which could be used to fill this therapeutic void without challenging psychiatric authority. It may also bear repeating that, in the mixed healthcare system of the Irish Free State of this time, the fact that AA did not charge fees or threaten the earning capacity of private psychiatric practitioners was highly significant.

On the wider question of promoting the idea of alcoholism as a disease, Sackville's learning curve was considerably more gradual. A striking feature of the early correspondence between Dublin AA and the New York secretariat is that it was the Irish group which spoke blithely of alcoholism as a disease, while the staff of the New York office advised caution in this regard. Commenting to Sackville (June 15, 
1948) on a leaflet which he had produced as part of his public relations campaign, Bobbie Burger wrote:

I note in this leaflet that you refer to alcoholism as a disease. This definition is becoming more common but you may have seen we still do not use the word "disease". The medical profession is arguing about it, and until they come to some kind of decision, we are keeping hands off in line with our policy of staying away from anything of a controversial nature. You will note in our writings we refer to alcoholism either as an "illness" or as a "malady". This is just a suggestion for you people but do as you please [28].

In his reply Sackville was sardonic: 'I apologise humbly for the word Disease. Please substitute illness or malady wherever necessary. The doctors here have no objections so far to its use, and it makes for simplification' [29]. Another of the New York office staff, Ann Lehman, reinforced this cautionary note, telling Sackville: 'I will have to join Bobbie and Charlotte in shying away from the word "disease" ' [30]. Sackville merely responded that he was 'far too happy in A.A. to bother whether the correct term is bubonic plague or otherwise' [31]. What Sackville came to realise was that underlying this disagreement, which he initially saw as nothing other than a semantic quibble, was a serious policy issue relating to the fellowship's decision not to become embroiled in controversy by lobbying to have the disease concept enshrined in public policy.

In Ireland policy support for the notion that alcoholism was a disease developed incrementally until the mid-1960s, prompted mainly by the World Health Organisation (WHO) which had started to disseminate this concept internationally during the early-1950s. It was not, however, until 1960 that an Irish governmental figure referred explicitly and positively to the disease concept, albeit within a politically controversial context which might be seen as confirming AA's wisdom in not becoming involved in lobbying of this kind. In 1959 the Government had published a bill which proposed to liberalise the country's licensing laws, previous attempts to do this having been easily defeated by the Catholic Church (Whyte [32]). The Church's opposition to these legislative proposals was led by Archbishop McQuaid who personally drafted the bishops' memorandum to Government, arguing that increased access to alcohol would result in higher consumption and a higher prevalence of related problems [33]. In answering his ecclesiastical critics, the 
Minister for Justice drew explicitly on a 1952 alcoholism sub-committee report of the WHO to the effect that increased alcohol consumption has no causal significance in relation to the prevalence of alcoholism [34]. The Intoxicating Liquor Act, 1960, was the first, and for many years the only, occasion on which an Irish Government simply ignored a directive of the Catholic bishops. In view of the use made of the disease concept by the Government to justify its actions, it was obviously helpful to AA that it had not become embroiled in this Church-State conflict.

Despite the 'near miss' nature of this episode which might easily have drawn the fellowship into political controversy, Sackville continued for several more years to be uncritically positive about the role which AA members might play in a putative Irish lobby group comparable to the National Council on Alcoholism in the United States. He played a lead role in organizing a visit to Ireland in 1964 by Marty Mann, founder of this American body, and collaborated with various other stakeholders in the creation of the Irish National Council on Alcoholism (INCA). However, by the end of 1965 - even before it had established itself as a legal entity - Sackville appears to have become disillusioned with INCA, telling Bill W. in his Christmas Day letter: 'Richard has come back to settle down in Dublin again, and that should be a great help, even if he is involved in the attempt to form a Marty Mann Council over in Ireland' [35]. At the time of its legal establishment as a company, there were seven subscribers to INCA's memorandum of association: one was the Chief Justice; two (Sackville and Aiden MacS.), although they did not acknowledge themselves as such, were AA members; and four were consultant psychiatrists based in private hospitals. As Executive Director of INCA, Richard P. shed his anonymity; although he did not acknowledge himself as a member of AA, it would probably have been clear to interested observers that he was in the fellowship since it was mainly AA members who appeared happy to tell the world about their alcoholism. In his letters to New York, Sackville expressed increasing cynicism about INCA, suggesting that AA members should not waste their time working outside the structures and culture of their own fellowship. A quote, from his 1969 Christmas Day letter to Bill W. illustrates this: 
Richard is concealed in the Irish National Council on Alcoholism and we hardly see him. There is a circus of so-called "experts" in Europe who go from one good conference, hotel-wise anyway, to another, to pool their knowledge, which has never seemed to me to very sufficient inasmuch as they can't tell us how we develop the disease nor prevent it nor cure it [36].

Sackville's initial enthusiasm for INCA appears to have been based upon an implicit belief that there was considerable opposition to the disease concept of alcoholism in Ireland. By the mid-1960s, this belief was questionable since public criticism of this concept appears to have been almost non-existent and it received explicit and unequivocal policy support in the report of the 1966 Commission of Inquiry on Mental Illness [37]. By the early-1970s, however, an ideological split had emerged within INCA: on one side were those who continued to see alcoholism as a discrete disease affecting only a minority of biologically predisposed drinkers; the other side consisted of those tending towards the emergent public health approach now being espoused by WHO, which emphasised the causal importance of population drinking levels and patterns for a spectrum of alcohol-related problems (Butler [12], pp. 5062). None of the subsequent Executive Directors were fellowship members, and following the departure of Sackville and Aiden MacS. from its committee, there was no apparent connection between AA and INCA.

Sackville's disillusionment with INCA reflected a mixture of instinctive cynicism about the motives of those involved in this organisation and a growing understanding of why its Traditions urged members to maintain clear boundaries between AA and other organisations. By 1968 he was explaining to an AA friend in Chicago that he disapproved of any overlap between AA activities and INCA activities: 'I don't believe it is our business to start educating the public about the disease of alcoholism ... It is our privilege to pass our Recovery and Hope message to other alcoholics, but surely not to turn ourselves into minnie [sic] Marty Manns or doctors' [38]. The isolationist path followed thereafter by AA in Ireland was broadly similar to that of AA in its country of origin and fully in keeping with the Tenth Tradition, which makes it clear that AA has no opinion on 'outside issues' and that 'the AA name ought never be drawn into public controversy'. 


\section{DISCUSSION AND CONCLUSION}

While Valverde and White-Mair [5] acknowledge that AA may validly be seen as challenging of conventional authority (and in an American context particularly of medical authority), they primarily characterise AA as a pragmatic movement: that is, a movement which emphasises practice - mainly going to meetings and 'working' the programme - rather than theory, belief or explanation. The specific circumstances confronting early AA members in Ireland were, on the one hand, a healthcare system with no definite therapeutic philosophy as to the management of drinking problems and no prior experience of mutual help associations, and, on the other, a dominant religious institution unaccustomed to challenge or criticism of any kind. What the archival material presented here largely shows is that it was this pragmatic streak in AA which allowed it to avoid conflict with both the healthcare system and the Catholic Church during its early years in Ireland: the fellowship presented itself as solely concerned with making contact with such problem drinkers as were willing to attend its meetings, without seeking to promote either a scientific model of alcoholism or a specific religious doctrine. On the healthcare side, AA moved within a few brief years from its initial rejection by the first two hospitals which it had approached to a position where psychiatrists sought its advice; on the religious side, not only did it avoid direct attack from religious leaders, but within a few years members were being invited to lecture seminarians and to contribute journal articles in the field of pastoral theology. This pragmatism, although slower to emerge in relation to macro policy issues, meant that AA had disengaged from INCA by the early-1970s, before the policy tensions between adherents of the disease concept and those who favoured a public health perspective had become too pointed.

'Great Man' theories of history are always suspect, and perhaps never more so than in the history of a movement which insists on anonymity and on 'principles before personalities'. It has to be acknowledged, however, that AA in Ireland was well served by Sackville, who over twenty five years discovered - and periodically rediscovered that the fellowship is solely concerned with individual change and has no overt interest in political, economic or religious systems. It is perhaps this feature of AA which best explains how it adapted to mid-twentieth century Ireland and why there appear to be few limits to its global diffusion. 


\section{ACKNOWLEDGEMENTS}

The authors would like to thank the following for their assistance in researching this paper: the Trustee's Archives Committee of the AA General Service Office, New York, for permission to consult its extensive collection of early correspondence between members in Dublin and the New York headquarters of AA, and Michelle Mirza, assistant archivist at the New York archive, for her practical help with this project; the Archives Committee of the General Service Board of AA Ireland for permission to consult its Dublin archive; David Sheehy, archivist at the Dublin Diocesan Archives for his help in locating relevant records from the McQuaid Papers; the staff of the Library at Trinity College Dublin. At the School of Social Work and Social Policy, Trinity College Dublin, Pam Isaacson provided administrative support, and Marguerite Woods and Barry Cullen read and made helpful comments on an early draft of this paper. In deference to AA's tradition of anonymity, individual members have been referred to here simply by their first names and family name initials.

\section{REFERENCES}

1. Kurtz, E. (1991) Not-God: A History of Alcoholics Anonymous (expanded edition). Center City, Minnesota: Hazelden.

2. Eisenbach-Stangl, I. and Rosenqvist, P. (1998) Diversity in Unity: Studies of Alcoholics Anonymous in Eight Societies. Helsinki: Nordic Council for Alcohol \& Drug Research.

3. Makela, K., Arminen, I., Bloomfield, K., Eisenbach-Stangl, I., Helmerssson Bergmark, K., Kurube, N., Mariolini, N., Olafsdottir, H., Peterson, J., Phillips, M., Rehm, J., Room, R., Rosenqvist, P., Rosovsky, H., Stenius, K., Swiatkiewicz, G., Woronowicz, B. and Zielinski, A. (1996) Alcoholics Anonymous as a Mutual-Help Movement: A Study in Eight Societies. Madison: The University of Wisconsin Press.

4. Levine, H.G. (1992) Temperance cultures: concern about alcohol problems in Nordic and English-speaking cultures. In: Lader, M., Edwards, G. and Drummond, D.C. eds. The Nature of Alcohol and Drug Related Problems, 1536. Oxford: Oxford University Press. 
5. Valverde, M. and White-Mair, K. (1999) 'One Day At A Time' and Other Slogans For Everyday Life: The Ethical Practices Of Alcoholics Anonymous. Sociology, 33, 393-410.

6. Inglis, T. (1998) Moral Monopoly: The rise and fall of the Catholic Church in Modern Ireland ( $2^{\text {nd }}$ ed.). Dublin: University College Dublin Press.

7. Cooney, J. (1999) John Charles McQuaid: Ruler of Catholic Ireland. Dublin: The O'Brien Press.

8. Keogh, D. and McCarthy, A. (2005) The Catholic Church and the Writing of the 1937 Constitution. History Ireland, 13 (3), 36-41.

9. Malcolm, E. (1986) Ireland Sober, Ireland Free: Drink and Temperance in Nineteenth-Century Ireland. Dublin: Gill and Macmillan.

10. Ferriter, D. (1999) A Nation of Extremes: The Pioneers in Twentieth-century Ireland. Dublin: Irish Academic Press.

11. Finnane, M. (1981) Insanity and the Insane in Post-Famine Ireland. London: Croom Helm.

12. Butler, S. (2002) Alcohol, Drugs and Health Promotion in Modern Ireland. Dublin: Institute of Public Administration.

13. Alcoholics Anonymous (1986) Alcoholics Anonymous in Ireland, 1946-1986. Dublin: Alcoholics Anonymous General Service Board.

14. Alcoholics Anonymous (1996) Golden Jubilee, 1946 -1996: Fifty Years a Growing. Dublin: Alcoholics Anonymous General Service Board.

15. Audio-Tape of Talk by Conor F. at Dublin AA's $21^{\text {st }}$ Birthday Celebration. Alcoholics Anonymous Archive, Dublin.

16. Malcolm, E. (1989) Swift's Hospital: A History of St. Patrick's Hospital Dublin 1746-1989. Dublin: Gill and Macmillan.

17. Letter from Richard P. to Bobbie Burger (December 11, 1946). Alcoholics Anonymous Archives, New York.

18. Letter from Bobbie Burger to Richard P. (December 20, 1946). Alcoholics Anonymous Archives, New York.

19. Letter from Richard P. to Bobby Burger (May 6, 1947). Alcoholics Anonymous Archives, New York.

20. Letter from Bobby Burger to Richard P. (May 15, 1947). Alcoholics Anonymous Archives, New York. 
21. Letter from Sackville to Bill W. (January 6, 1950). Alcoholics Anonymous Archives, New York.

22. O'Riordan, S. (1962) Alcoholism. In: O’Doherty, E.F. and McGrath, S.D. eds. The Priest and Mental Health, 150-154. Dublin: Clonmore and Reynolds.

23. Letter from Sackville to Bill W. (April 28, 1961). Alcoholics Anonymous Archives, New York.

24. A Dublin Member of Alcoholics Anonymous (1972) The Vatican and Alcoholics Anonymous. The Furrow, 23, 181-183.

25. Letter from Sackville to Bobbie Burger and Charlotte Lappen (October 1, 1947). Alcoholics Anonymous Archives, New York.

26. Letter from Sackville to Bobbie Burger (September 20, 1947). Alcoholics Anonymous Archives, New York.

27. Letter from Sackville to Bobbie Burger (June 5, 1948). Alcoholics Anonymous Archives, New York.

28. Letter from Bobbie Burger to Sackville (June 15, 1948). Alcoholics Anonymous Archives, New York.

29. Letter from Sackville to Bobby Burger (September 9, 1948). Alcoholics Anonymous Archives, New York.

30. Letter from Ann Lehman to Sackville (October 6, 1948). Alcoholics Anonymous Archives, New York.

31. Letter from Sackville to Bobby Burger, Charlotte Lappen and Ann Lehman (October 11, 1948). Alcoholics Anonymous Archives, New York.

32. Whyte, J. (1971) Church and State in Modern Ireland 1923-1970. Dublin: Gill and Macmillan.

33. Folder on Episcopal Delegation concerning the Licensing Laws. McQuaid Papers, Archives of the Catholic Archdiocese of Dublin.

34. Dail (Irish Parliament) Debates (1959) Volume 177, columns 948-949.

35. Letter from Sackville to Bill W. (December 25, 1965). Alcoholics Anonymous Archives, New York.

36. Letter from Sackville to Bill W. (December 25, 1969). Alcoholics Anonymous Archives, New York.

37. Commission of Inquiry on Mental Illness. (1966) Dublin: Stationery Office.

38. Letter from Sackville to Joe D. (a Chicago-based AA member) (April 11, 1948). Alcoholics Anonymous Archives, Dublin. 